\title{
Corrigendum to "Assessment of School Readiness in Chronic Cholestatic Liver Disease: A Pilot Study Examining Children with and without Liver Transplantation"
}

\author{
Anna Gold, ${ }^{1,2}$ Alaine Rogers, ${ }^{3,4}$ Elizabeth Cruchley, ${ }^{1}$ Stephanie Rankin, ${ }^{1,5}$ Arpita Parmar, ${ }^{1,5}$ \\ Binita M. Kamath, ${ }^{1,5,6}$ Yaron Avitzur, ${ }^{1,5,6}$ and Vicky Lee $\mathrm{Ng}^{1,5,6}$ \\ ${ }^{1}$ Transplant and Regenerative Medicine Centre, Hospital for Sick Children, Toronto, ON, Canada \\ ${ }^{2}$ Department of Psychology, Hospital for Sick Children, Toronto, ON, Canada \\ ${ }^{3}$ Department of Rehabilitation, Hospital for Sick Children, Toronto, ON, Canada \\ ${ }^{4}$ Department of Occupational Science and Occupational Therapy, University of Toronto, Toronto, ON, Canada \\ ${ }^{5}$ Division of Pediatric Gastroenterology, Hepatology and Nutrition, Hospital for Sick Children, Toronto, ON, Canada \\ ${ }^{6}$ Department of Pediatrics, University of Toronto, Toronto, ON, Canada
}

Correspondence should be addressed to Elizabeth Cruchley; elizabeth.cruchley@sickkids.ca

Received 20 May 2017; Accepted 24 May 2017; Published 12 July 2017

Copyright (C) 2017 Anna Gold et al. This is an open access article distributed under the Creative Commons Attribution License, which permits unrestricted use, distribution, and reproduction in any medium, provided the original work is properly cited.

In the article titled "Assessment of School Readiness in Chronic Cholestatic Liver Disease: A Pilot Study Examining Children with and without Liver Transplantation" [1] there was an error in the Abstract, where the statement "Median Full-Scale IQ was 98 (range 102-116) for LT and 116 [(range $90-106), p=0.35, \mathrm{NS}]$ for NL subjects" should be corrected to "Median Full-Scale IQ was 98 (range 90-106) for LT and 116 [(range 102-116), $p=0.35, \mathrm{NS}]$ for NL subjects."

\section{References}

[1] A. Gold, A. Rogers, E. Cruchley et al., "Assessment of school readiness in chronic cholestatic liver disease: a pilot study examining children with and without liver transplantation," Canadian Journal of Gastroenterology and Hepatology, vol. 2017, Article ID 9873945, 8 pages, 2017. 


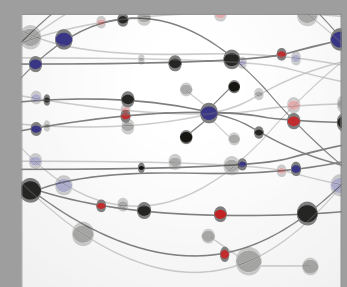

The Scientific World Journal
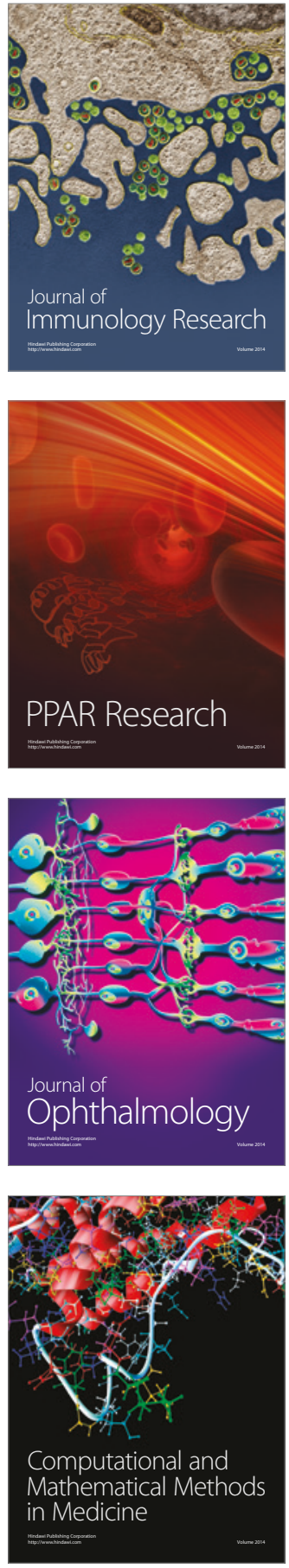

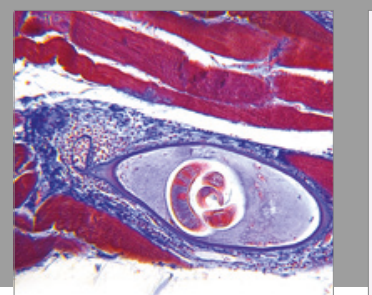

Gastroenterology Research and Practice
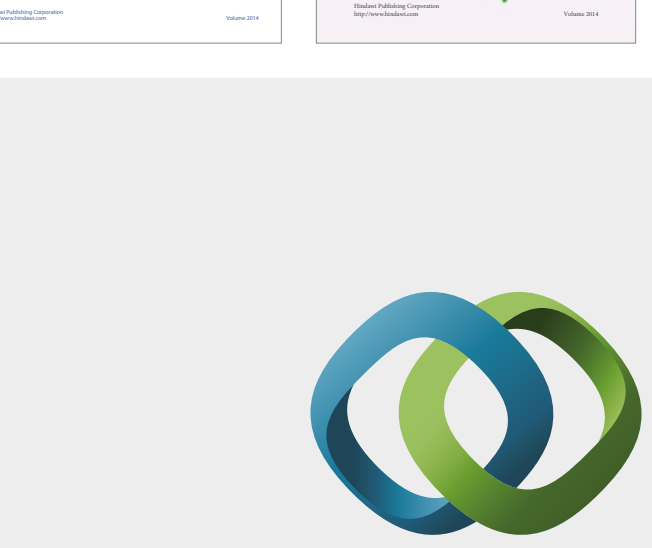

\section{Hindawi}

Submit your manuscripts at

https://www.hindawi.com
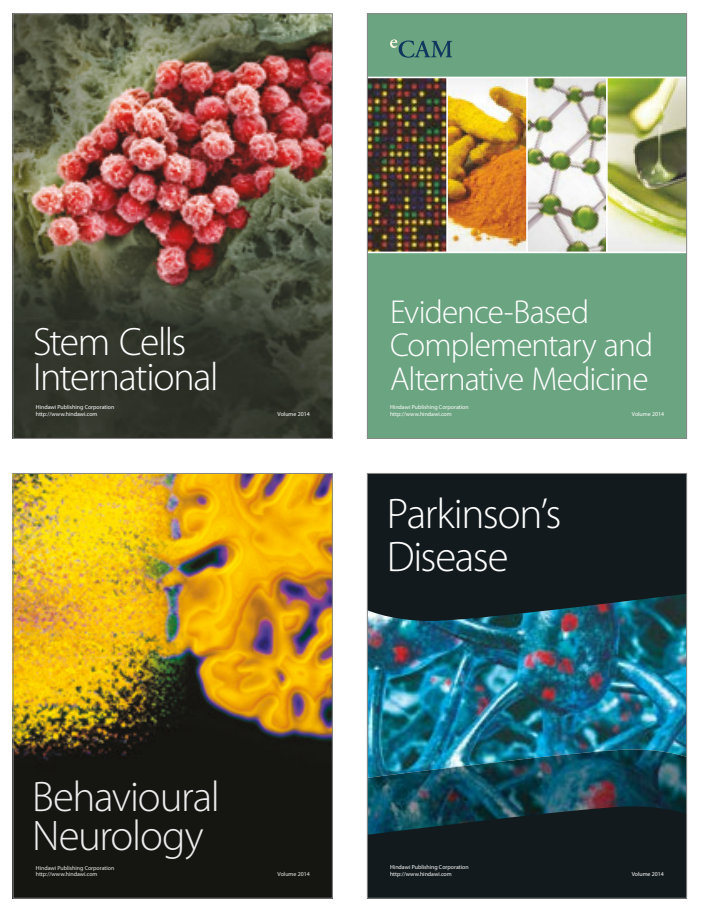
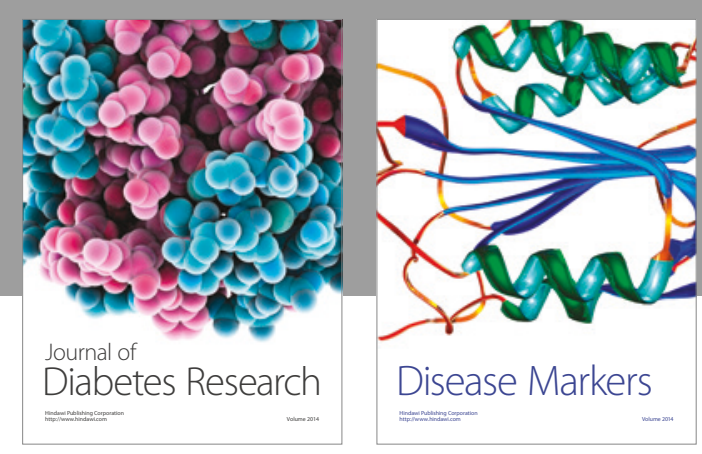

Disease Markers
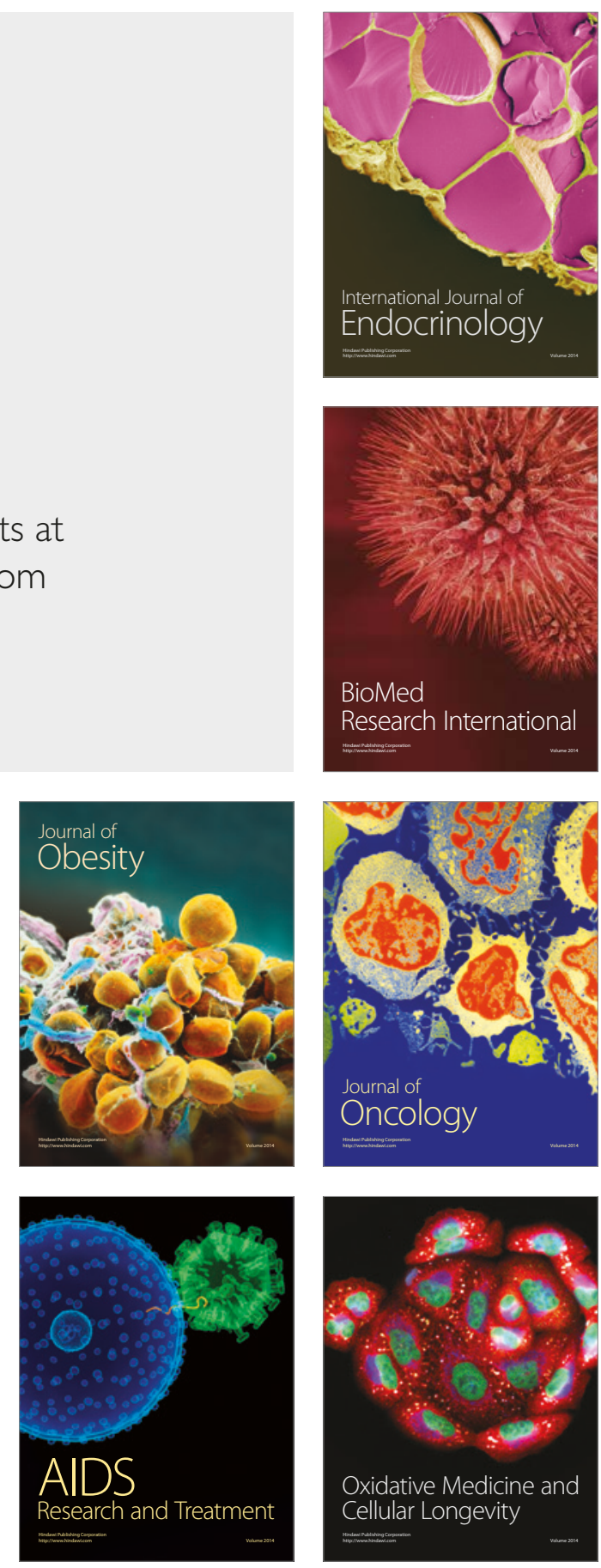